\title{
Movimentos SOCIAIS E POLÍTICAS PÚBLICAS DE EDUCAÇÃO PARA AS POPULAÇÕES QUE HABITAM NO MEIO RURAL
}

\author{
Social movements and public policies of education for \\ people living in rural areas
}

\begin{abstract}
RESUMO O objetivo deste artigo é apontar a luta desenvolvida pelos movimentos sociais em busca da implementação de políticas públicas para assegurar o direito de acesso e permanência à escola para as populações que vivem no meio rural brasileiro. Optamos por realizar uma pesquisa teórica, pois compreendemos que os documentos constituem fonte perene da qual podemos retirar as evidências para sustentar as nossas declarações e argumentações, visto que fornecem as mais diversas informações acerca de um contexto histórico determinado. Focalizamos as nossas investigações e análises em escritos de pesquisadores que se dedicaram ao estudo da educação do campo, à legislação nacional e aos relatórios resultantes dos fóruns nacionais sobre educação do campo. O êxito em defesa da educação do campo é evidente, contudo, parcial, pois esbarra na forma do reconhecimento e da implantação das políticas públicas por parte do Estado, evidenciadas pela distância que mantêm das reais reivindicações dos movimentos sociais.
\end{abstract}

PalaVRAS-CHAVE: MoVIMENTOS SOCIAIS; DiREITO À EdUCAÇÃO; EdUCAÇÃO DO CAMPO.

ABSTRACT The purpose of this article is to point out the struggle developed by social movements in pursuit of implementation of public policies to ensure the right of access and permanence to school for people living in rural areas. We chose to perform a theoretical research, because we understand that documents are perennial source from which we can withdraw the evidence to support our statements and arguments, since it provides the most diverse information about a particular historical context. We focus our researches and analyses in the writings of researchers dedicated to the study of education field, to the national legislation and the resulting reports of the national forums on education of the field. The success in defense of education field is evident, however, in part, because coming up in the form of the recognition and the implementation of public policies on the part of the state, evidenced by the distance that keeps the real demands of the social movements.

KEYWORDS: SOCIAL MOVEMENTS; RIGHT TO EDUCATION; FIELD EDUCATION.
Flávio Reis Santos ${ }^{I}$ Luiz Bezerra Neto II

'Universidade Estadual de Goiás (UEG), Morrinhos/ GO - Brasil

IIUniversidade Federal de São Carlos (UFSCar), São Carlos/ SP - Brasil

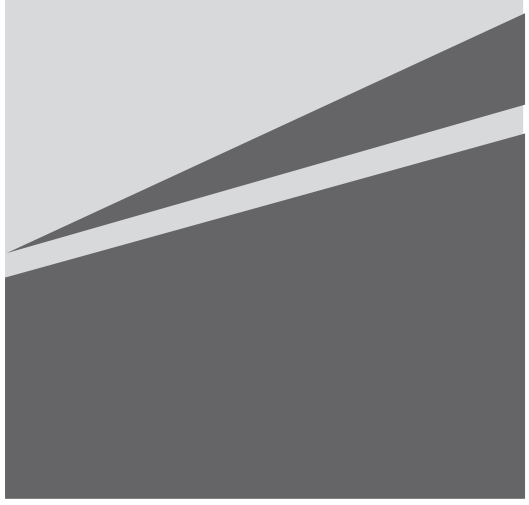




\section{INTRODUÇÃO}

A s políticas públicas expressam a materialização dos direitos sociais do homem em sua universalidade, mas é preciso tomar conhecimento acerca de quais estratégias e recursos devem ser utilizados para fazer que o Estado assuma as suas responsabilidades e execute as suas funções na elaboração e na implantação dessas políticas, a partir da consideração das diferentes condições econômicas, sociais e culturais das populações a que se destinam com vistas a assegurar o acesso aos direitos.

Entender a acepção e a importância da realização das políticas públicas em prol da classe trabalhadora no contexto da sociedade capitalista neoliberal e neoconservadora representa compreender a garantia do direito aos bens e aos serviços públicos, neste caso, o direito de acesso à educação e à permanência na escola de boa qualidade.

$\mathrm{Na}$ apreensão de Miguel Arroyo (2005, p. 3), a educação precisa ser entendida como recurso fundamental à população brasileira, devidamente reconhecida como sujeito de direitos; de se constituir e se formar como gente; de gente que tem cara e que tem história; e, neste sentido, evoluir e unificar as forças de e entre todos os movimentos sociais que empreendem luta em defesa da educação como direito do homem e como direito universal inalienável.

O Estado, de uma parte, tem a competência de viabilizar e propiciar o direito à educação e garantir a sua oferta a todos, de acordo com os dispositivos da Constituição da República Federativa do Brasil de 1988 (CF 1988) e da Lei de Diretrizes e Bases da Educação Nacional de 1996 (LBD 1996). De outra parte, é dever da sociedade lutar em defesa da garantia de direitos históricos e concretos.

É imprescindível a defesa do direito à educação como direito universal, como direito "datado, situado num lugar, numa forma de produção, na produção familiar, na produção rural", pois os sujeitos possuem trajetórias de vida, "de classe, de gênero, de etnia, de raça, em que vão se construindo como trabalhadores, como sujeitos históricos concretos" (ARROYO, 2005, p. 3). Nesse sentido, apontamos a necessidade da retomada e permanência na luta por parte dos movimentos sociais para a efetivação dos direitos, visto que a sua concretização manifesta, exprime, representa a luta permanente como sujeitos históricos; de outro modo, continuaremos em defesa de direitos abstratos, "direitos de gente sem rosto, sem trajetória, sem história, sem cor, sem gênero, sem classe" (ARROYO, 2005, p. 3).

Ressaltamos que o princípio de igualdade das condições de acesso e permanência na escola - disposto no artigo 206 da Constituição Federal de 1988 - "constitui diretriz que deve informar o conjunto das políticas educacionais e deve ser tomado como base para a proposição de políticas afirmativas para a efetiva garantia do direito à educação" (MOLINA, 2008, p. 28). A dinâmica e a complexidade das condições econômicas, políticas, sociais e culturais das populações rurais requerem, nesses termos, de "maior coerência na construção de estratégias que visem alavancar a qualidade da educação do campo", no campo, no meio rural e na sociedade em sua totalidade (MOLINA, 2008, p. 28).

A igualdade pressupõe a disponibilidade de oportunidades em condições que se assemelham para garantir o mesmo nível de direitos, situação que não encontramos em nosso país com frequência ao compararmos as condições ofertadas às populações do meio urbano com aquelas ofertadas às populações do meio rural. O direito não exige apenas a simples e mera igualdade, mas, sobretudo, a sua garantia, a sua universalidade, o "respeito à diversidade encontrada no trato das questões culturais, políticas e econômicas do meio rural", na medida em que é exatamente "a especificidade das condições de acesso e as desigualdades no acesso à educação, que necessariamente demandam ações afirmativas do Estado para corrigir as distorções históricas" (MOLINA, 2008, p. 29).

As políticas de educação precisam e devem ser universalizantes, precisam e devem 
ser específicas para que populações em situação de vulnerabilidade tenham assegurado o acesso aos direitos previstos na legislação brasileira. A garantia de acesso diferenciado à educação segundo Clarice Duarte (2008, p. 37), não consubstancia um privilégio, "mas uma política que pode ser justificada racionalmente a partir de uma situação de igualdade, a partir da realização de diagnóstico da situação, o que justifica a proteção especial a determinados grupos".

Portanto, garantir o direito à educação para as populações do campo constitui um desafio permanente para os movimentos sociais, visto que as suas diversidades e as suas especificidades constituem as bases materiais da ação coletiva para a transposição histórica do descaso, da precarização e da marginalização da educação rural, bem como, para a elaboração de políticas públicas de educação que levem em consideração a existência, a trajetória, a história, as dinâmicas e as complexas realidades dos sujeitos que vivem e trabalham no campo.

É nesta direção que a ação e atuação coletivas dos movimentos e organizações sociais da classe trabalhadora do campo, universidades públicas, instituições internacionais, organizações da sociedade civil e órgãos do poder público podem contribuir e, têm em determinada escala, contribuído para o fortalecimento da luta ao reconhecimento e à valorização da educação para as populações rurais como direito; para a educação rural como política pública nacional, traduzida e materializada em programas governamentais que vêm sendo implantados em nosso país desde o final da década de 1990, mais especificamente, após a ocorrência do I Encontro Nacional de Educadores da Reforma Agrária (ENERA), realizado na cidade de Luziânia, Estado de Goiás, em julho de 1997.

Todavia, não podemos incorrer em erro de reduzir a nossa compreensão de que a educação para as populações rurais possa concentrar-se numa concepção pedagógica de "fixação" à terra, ao campo, ao meio rural. Precisamos externalizar que a luta em defesa de uma formação escolar ampla e universalizante para os sujeitos do campo representa primeiramente problemática econômica, visto que as prioridades da classe dominante concentram-se na reprodução e manutenção do capital em suas mãos e não na satisfação das necessidades para assegurar a existência e os direitos da classe trabalhadora.

Chamamos a atenção, ainda, para o fato de que o Estado, por meio de sua estrutura burocrático-administrativa e dos seus mecanismos de fiscalização e controle, historicamente, esteve (está) a serviço da classe dominante. Portanto, é necessária a apreensão do papel desempenhado pelas políticas públicas estatais, na medida em que elas procuram atender parcialmente às reivindicações dos movimentos sociais organizados, mas sem perder de vista a satisfação das demandas impostas pelo capitalismo.

\section{A LUTA EM DEFESA DA EDUCAÇÃO DO CAMPO}

Os movimentos sociais e as organizações dos trabalhadores rurais - aqui entendidos por agricultores familiares, trabalhadores assalariados, comunidades tradicionais, extrativistas, ribeirinhos, pescadores artesanais, povos atingidos por barragens, da floresta, acampados, assentados e comunidades remanescentes de quilombos - têm se envolvido na luta e conquista pela terra, no fortalecimento da produção agrícola familiar, na busca pelo direito a uma existência digna e à educação de qualidade no seu local de moradia ou próxima a ele. Nessa trajetória, Salomão Mufarrej Hage (2014) destaca a efetiva atuação do Movimento Nacional de Educação do Campo para evitar a formulação e instituição de políticas compensatórias e assistencialistas, que insistem na manutenção da precarização das escolas do meio rural, reafirmando:

[...] o atraso e o abandono da educação dos povos que vivem da agricultura, do extrativismo e da pesca, ao reivindicar que as experiências político-pedagógicas acumuladas 
nesse processo de luta e mobilização, de tomada de posição nos confrontos entre concepções de agricultura, de projetos de campo, de educação e de lógica de formulação de políticas públicas sejam reconhecidas e legitimadas pelo sistema público em suas várias esferas (HAGE, 2014, p. 134).

É na esteira desse processo, que localizamos as origens do Movimento em Defesa da Educação do Campo, a saber: I Encontro Nacional de Educadores na Reforma Agrária (Brasília/DF, 1997); I Conferência Nacional Por uma Educação Básica do Campo (Luziânia/ GO, 1998); I Seminário do Programa Nacional de Educação na Reforma Agrária (Luziânial GO, 2003); I Conferência Nacional Por uma Educação Básica do Campo: Por Uma Política Pública de Educação do Campo (Luziânia/GO, 2004), reivindicando junto ao Estado a construção e implementação de políticas públicas para atender às demandas por educação para as populações rurais de nosso país.

A primeira conquista decorrente da trajetória de mobilização e lutas empreendidas pelos movimentos sociais, na expressão de sua constitucionalidade, pode ser expressa pelo Programa Nacional de Educação na Reforma Agrária (PRONERA), visto que representa marco substancial na busca do direito à educação para os sujeitos que vivem no e do meio rural e, por desempenhar função de grande importância para contribuir com a diminuição das desigualdades escolares, sociais e econômicas brasileiras, na medida em que procura viabilizar a implantação de políticas públicas que garantam o acesso à educação básica e superior, à formação profissional, à formação de educadores e à defesa da escola pública de educação básica em áreas rurais.

O Movimento de Educação do Campo, de acordo com as argumentações de Roseli Caldart (2008, p. 71), ergue-se a partir do momento em que assume um posicionamento contrário à "lógica do campo como lugar de negócio, que expulsa as famílias, que não pre- cisa de educação nem de escolas porque precisa cada vez menos de gente", reforçando a dinâmica produtiva "para a sustentação da vida em suas diferentes dimensões, necessidades, formas". A construção da educação do campo em meio à luta em defesa de direitos coletivos relacionados e contidos no âmbito público reitera a oposição e o não contentamento de medidas e ações de cunho assistencialista, visto que "não se trata de qualquer política pública, o debate é de forma, conteúdo e sujeitos envolvidos" na luta para assegurar os seus direitos (CALDART, 2008, p. 72).

Não é demasiado ratificar que a educação do campo é decorrência da mobilização e protagonismo dos movimentos sociais pela construção e implantação de políticas educacionais para as populações rurais. A educação do campo é resultado da combinação das lutas empreendias pelo Movimento dos Trabalhadores Rurais Sem Terra pela instalação "de escolas públicas nas áreas de reforma agrária com as lutas de resistência de inúmeras organizações e comunidades camponesas para não perder suas escolas, suas experiências de educação, seu território, sua identidade", argumenta Roseli Caldart (2008, p. 71).

Por seu turno, Maria do Socorro Silva (2006, p. 86), infere que o envolvimento e a participação dos movimentos sociais do campo em "conselhos e outros espaços institucionais de interlocução entre o Estado e a sociedade, formulando e realizando o controle social das políticas" têm contribuído para a "construção de novas institucionalidades para a gestão social das políticas públicas em busca de articular a participação nestes espaços com outras ações dos movimentos, com os seus processos organizativos, capacidade mobilizadora e formativa".

Nesse sentido, os movimentos sociais, entendidos como sujeitos coletivos, têm apresentado demandas materiais que provocaram em determinada medida, a renovação do sistema político brasileiro, dentre as quais é possível citar o Programa Nacional de Agricultura Familiar (PRONAF), o 
Programa Nacional de Educação na Reforma Agrária (PRONERA), a criação da Coordenação Geral de Políticas de Educação do Campo da Secretaria de Educação Continuada, Alfabetização, Diversidade e Inclusão do Ministério da Educação (SECADI/MEC).

Em convergência às argumentações de Roseli Caldart (2008) e de Maria Silva (2006), Salomão Hage (2014) aponta que os movimentos sociais e, especialmente, o Movimento de Educação do Campo acumulou por sua trajetória de lutas em âmbito nacional, estadual e municipal, um significativo conjunto de instrumentos para a legalização e legitimação das experiências educativas das populações rurais. Experiência fundamental para o exercício do direito à universalização da educação para os sujeitos que vivem no e do campo.

O envolvimento e participação do Movimento em Defesa da Educação do Campo em discussões no e do Ministério da Educação (MEC), Conselho Nacional de Secretários de Educação (CONSED), União Nacional dos Dirigentes Municipais de Educação (UNDIME), Conselhos Estaduais e Municipais de Educação, Conselho Nacional de Desenvolvimento Rural Sustentável (CONDRAF), instituições de ensino e pesquisa e organizações não governamentais resultaram na aprovação das Diretrizes Operacionais para a Educação Básica do Campo (Resolução CNE/CEB n. 1/2002).

$\mathrm{O}$ disposto no artigo $2^{\circ}$ das Diretrizes Operacionais para a Educação Básica do Campo exprime a sua constituição a partir de "um conjunto de princípios e procedimentos que visam adequar o projeto institucional das escolas do campo às Diretrizes Curriculares Nacionais", considerando a identidade da escola do campo, "definida pela sua vinculação às questões inerentes à sua realidade", orientada pelos saberes e temporalidades próprias dos estudantes, bem como na memória coletiva dos povos do campo, pela "rede de ciência e tecnologia disponível na sociedade e nos movimentos sociais em defesa de projetos que associem as soluções exigidas por estas questões à qualidade social da vida coletiva do país" (BRASIL, 2002, § único).
As propostas pedagógicas para as escolas e das escolas do campo, observadas as diferenças e o direito à igualdade e cumprimento imediato e pleno das especificações da Lei de Diretrizes e Bases da Educação Nacional (LDB 9.394/1996) e em conformidade com o artigo $5^{\circ}$ das Diretrizes Operacionais para a Educação do Campo, deverão contemplar as diversidades do meio rural em seus "aspectos sociais, culturais, políticos, econômicos, de gênero, geração e etnia" e ser "desenvolvidas e avaliadas sob a orientação das Diretrizes Curriculares Nacionais para a Educação Básica" (BRASIL, 2002). Apontamos mais algumas regulamentações legais que são de grande importância no processo de conquistas em defesa do direito à educação para as populações que vivem em áreas rurais:

O Parecer CNE/CBE n. 1 (01/02/2006) passou a considerar dias letivos para a aplicação da Pedagogia da Alternância nos Centros Familiares de Formação por Alternância (CEFFAs) e admitiu que a Pedagogia da Alternância foi introduzida em nosso país no ano de 1969 pelo Movimento de Educação Promocional do Espírito Santo (MEPES) e pelos Centros Familiares de Formação por Alternância e se espalharam pelo território nacional, atingindo Estados do Norte, Nordeste, Centro-Oeste, Sudeste e Sul. Esclarecemos, que os CEFFAs que oferecem educação escolar apresentam as seguintes formas de organização:

a) Escolas Famílias Agrícolas (EFA): com 123 centros, presentes em dezesseis Estados brasileiros, desenvolvendo os anos finais (segundo segmento) do Ensino Fundamental, Ensino Médio e Educação Profissional Técnica de nível médio; b) Casas Familiares Rurais (CFR): com 91 centros, presentes em seis Estados, desenvolvendo os anos finais (segundo segmento) do Ensino Fundamental, Ensino Médio e Educação Profissional Técnica de nível técnico; c) Escolas Comunitárias Rurais (ECOR): com 3 centros no 
Espírito Santo desenvolvendo os anos finais (segundo segmento) do Ensino Fundamental; d) Escolas de Assentamentos (EA): com 8 centros no Estado do Espírito Santo, desenvolvendo os anos finais (segundo segmento) do Ensino Fundamental; e) Casas das Famílias Rurais (CDFR): com 3 centros situados nos Estados da Bahia, Pernambuco e Piauí, desenvolvendo os anos finais (segundo segmento) do Ensino Fundamental (BRASIL, 2006, p. 2).

Os CEFFAs se organizam em três grandes entidades: a União Nacional das Escolas Famílias Agrícolas do Brasil (UNEFAB), a Associação Regional das Casas Familiares Rurais do Sul do Brasil (ARCAFAR Sul) e a Associação Regional das Casas Familiares Rurais do Norte e Nordeste do Brasil (ARCAFAR Norte-Nordeste). É importante apresentar a nova disposição do artigo 23 da Lei de Diretrizes e Bases da Educação Nacional (LDB 9.394/1996), alterado a partir da publicação do Parecer $\mathrm{CNE} /$ CBE n. 1/2006, a saber:

A Educação Básica poderá organizar-se em séries anuais, períodos semestrais, ciclos, alternância regular de períodos de estudos, grupos não seriados com base na idade, na competência e em outros critérios, ou por forma diversa de organização, sempre que o interesse do processo de aprendizagem assim 0 recomendar (BRASIL, 2006).

$\mathrm{O} \oint 2^{\circ}$ do artigo 23 , por sua ordem, definiu que o calendário escolar deveria ser ajustado na conformidade das especificidades e necessidades locais, "inclusive climáticas e econômicas, a critério do respectivo sistema de ensino, sem com isso reduzir o número de horas letivas previsto na lei", ou seja, oitocentas horas/ano, distribuídas em duzentos dias letivos. O artigo 28 , por seu tempo, determinou a realização de adaptações aos sistemas de ensino de acordo com a realidade de vida das populações rurais na oferta da educação básica, em especial, no que se remete aos "conteúdos e metodologias apropriadas às reais necessidades e interesses dos alunos da zona rural, à organização escolar própria, incluindo adequação do calendário escolar às fases do ciclo agrícola e às condições climáticas e adequação à natureza do trabalho na zona rural" (BRASIL, 2006);

A segunda medida legal que merece destaque é a Resolução CNE/CEB n. 2 (28/04/2008), que estabeleceu diretrizes complementares ao desenvolvimento de políticas públicas para o atendimento à Educação Básica do Campo, compreendendo a oferta da educação infantil, o ensino fundamental, o ensino médio e técnico para os "agricultores familiares, extrativistas, pescadores artesanais, ribeirinhos, assentados e acampados da Reforma Agrária, quilombolas, caiçaras, indígenas e outros (BRASIL, 2008, artigo 1).

Chamamos a atenção para o contido no § 3 do artigo 6 dessa Resolução, ao reiterar que a responsabilidade pelo transporte escolar dos alunos da rede municipal é do município e a responsabilidade pelo transporte escolar dos alunos da rede estadual é do Estado. Contudo, o regime de colaboração entre os entes da federação deve ser realizado de acordo com a Lei n. 10.709/2003, ao prever que "em determinadas circunstâncias de racionalidade e economicidade, que os veículos pertencentes ou contratados pelos municípios também transportem alunos da rede estadual e vice-versa" (BRASIL, 2008). O planejamento da educação das escolas do campo deve ainda, considerar "as distâncias de deslocamento, as condições de estradas e vias, o estado de conservação dos veículos utilizados e sua idade de uso, a melhor localização e as melhores possibilidades de trabalho pedagógico com padrão de qualidade" (BRASIL, 2008);

A terceira regulamentação de grande importância na legislação brasileira sobre a educação do campo se refere à Resolução CNE/CEB n. 4 (13/07/2010), que estabeleceu as Diretrizes Curriculares Nacionais Gerais para a 
Educação Básica, mais especificamente, o disposto na Seção IV (Educação Básica do Campo), do Capítulo II (Modalidades da Educação Básica) ao reiterar os dispositivos da Resolução CNE/CEB n. 1/2002 e do Parecer CNE/ $C E B$ n. $1 / 2006$, atendendo às reivindicações dos movimentos sociais por uma educação para as populações do campo, definindo que as "formas de organização e metodologias pertinentes à realidade do campo devem ser acolhidas como a pedagogia da terra e a pedagogia da alternância" (BRASIL, 2010, artigo 36, § único).

Entendemos que a Pedagogia da Alternância configura uma das mais significativas estratégias para o oferecimento da educação básica e para o processo de expansão do ensino superior para as populações rurais, visto que se organiza pela associação de tempos distintos e espaços formativos, denominados "tempo escola" e "tempo comunidade", o que propicia aos trabalhadores rurais o acesso à formação escolar sem ter que abandonar o meio rural em que vive, reside e realiza as suas atividades produtivas;

Apontamos um último marco regulatório legal que, em nossa apreensão, contribuiu significativamente para o fortalecimento e consolidação da educação para os rurícolas: a publicação do Decreto n. 7.352, de 4 de novembro de 2010, que assegurou à educação do campo a condição de política de Estado destinada à ampliação e qualificação da oferta de educação básica e ensino superior às comunidades rurais, "desenvolvida pela União em regime de colaboração com os Estados, o Distrito Federal e os municípios, de acordo com as diretrizes e metas estabelecidas no Plano Nacional de Educação" (BRASIL, 2010).

A regulamentação do Programa Nacional de Educação na Reforma Agrária (PRONERA) como política estatal, concentrou no Governo Federal a responsabilidade pela elaboração e implantação de instrumentos que assegurem a manutenção e o desenvolvimento da educação no meio rural com vistas a transpor a defasagem histórica de acesso para diminuir o analfabetismo de jovens e adultos por meio da oferta de políticas de educação, agregando qualificação social e profissional ao ensino fundamental (BRASIL, 2010).

Nessa direção, reafirma-se a função de principal agente histórico dos movimentos sociais para instituição, regulação e regulamentação legal para o reconhecimento e efetivação da educação do campo como política pública estatal, materializada pelas Resoluções, Pareceres, Decretos e demais medidas empreendidas pelo governo brasileiro, traduzidas em programas e políticas de Estado que visam assegurar às populações rurais o direito à educação de boa qualidade por meio do PRONERA e do Programa Nacional de Educação do Campo (PRONACAMPO).

\section{EDUCAÇÃo NA REFORMA AGRÁRIA (PRONERA)}

O Programa Nacional de Educação na Reforma Agrária, criado no âmbito do extinto Ministério Extraordinário da Política Fundiária (MEPF), substituído pelo Ministério do Desenvolvimento Agrário (MDA), que, por seu tempo, foi sucedido pela Secretaria Especial de Agricultura Familiar e do Desenvolvimento Agrário e empreendido pelo Instituto Nacional de Colonização e Reforma Agrária (INCRA) com o propósito de promover a fortificação de uma política pública para a educação rural, destinada a atender aos beneficiários do Plano Nacional de Reforma Agrária (PNRA) e do Programa Nacional de Crédito Fundiário (PNCF).

A partir da publicação da Portaria n. 10, de 16 de abril de 1998, o PRONERA passou a defender e garantir o direito de acesso à escola pública para milhares de pessoas, trabaIhadoras rurais assalariadas, acampadas e assentadas de reforma agrária, que no decorrer de suas vidas não tiveram a oportunidade de alfabetização. Para além do acesso à educação pública de boa qualidade, o Programa Nacional de Educação na Reforma Agrária tem insistido e persistido em assegurar o direito à terra, ao território, à produção e à existência (CALDART, 2008).

Segundo as afirmações de Mônica Molina e Sonia de Jesus (2010, p. 32), o papel 
do PRONERA em defesa da elaboração e implantação das políticas públicas de educação do campo tem sido fundamental para "inseri-las na esfera da legitimidade e do confronto político da questão do campo e de seu desenvolvimento, como parte indissociável do tipo de desenvolvimento da própria nação brasileira".

De acordo com o disposto no artigo 13 do Decreto n. 7.352/2010, as populações alvo do PRONERA são os jovens e adultos de famílias beneficiárias dos projetos de assentamentos criados ou reconhecidos pelo INCRA; os estudantes de cursos de especialização (lato sensu) promovidos pelo INCRA; os professores que exercem atividades educacionais destinadas às famílias beneficiárias; e, as demais famílias cadastradas pelo INCRA.

Durante os anos de 1998 até 2011, o PRONERA desenvolveu projetos para a Educação de Jovens e Adultos (EJA), formação profissionalizante de nível médio e formação universitária. Foram realizados 320 cursos em 82 instituições de ensino em todo o Brasil: 167 de ensino fundamental, 99 de ensino médio e 54 de ensino superior. As consequências reais das ações do Programa para a formação escolar das populações rurais são verificadas pela quantidade de pessoas atendidas por parcerias e convênios firmados com inúmeras universidades em todo o território nacional (MOLINA; JESUS, 2010). No período 1998-2011, mais de 400 mil trabalhadores rurais foram escolarizados: da alfabetização ao ensino fundamental ou médio (técnico e profissionalizante) até a formação de nível superior em mais de 50 universidades.

Mônica Molina e Sonia de Jesus (2010) afirmam que, simultaneamente ao crescimento dos níveis de formação escolar realizados pelo PRONERA, procurou-se diversificar a oferta das áreas do conhecimento mediante parcerias firmadas com as universidades públicas para promover o desenvolvimento dos assentamentos e dos assentados. A prioridade foi concentrada em cursos de apoio ao trabalho produtivo, tendo em vista colaborar com a transformação das matrizes tecnológi- cas das áreas redefinidas e/ou reorganizadas, por exemplo:

[...] os cursos técnicos no âmbito da agroecologia e da administração de cooperativas e, também, os cursos de formação de educadores, como os de Magistério e Pedagogia da Terra, tendo em vista criar condições para a ampliação da oferta da Educação Básica no meio rural [...]. As necessidades de formação de profissionais foram se diversificando, relacionadas às diferentes demandas para a promoção do desenvolvimento dos assentamentos. Atualmente, em nível superior, realizam-se cursos em várias áreas, como Agronomia, Medicina Veterinária, Geografia, Enfermagem, História, Letras, Direito, Artes, Ciências Agrárias e Licenciatura em Educação do Campo (MOLINA; JESUS, 2010, p. 36).

Nesse sentido, o Programa Nacional de Educação na Reforma Agrária vem, sistematicamente, atingindo o seu principal objetivo, ou seja, assegurar o direito de acesso, permanência e consolidação da educação no campo, sobretudo nas áreas de reforma agrária e em decorrência do permanente estímulo, proposição, criação, desenvolvimento e coordenação de projetos educacionais. Do mesmo modo que a aplicação de metodologias focalizadas na especificidade das realidades do ambiente rural tem a perspectiva de colaborar para o resgate, imbricação e desenvolvimento do mundo acadêmico ao mundo rural (BRASIL, 2015).

Apesar de todas as dificuldades, entraves e adversidades, o Programa Nacional de Educação na Reforma Agrária se estabeleceu como política pública de educação para as populações rurais, reafirmando o seu propósito em "garantir aos sujeitos do campo o direto à educação por meio de um processo de escolarização que amplie cada vez mais as possibili- 
dades de autonomia e cidadania, com permanência no campo, produzindo e reproduzindo a vida com dignidade" (BRASIL, 2015 p. 15).

\section{PRONACAMPO}

Nos trilhos do PRONERA, a Secretaria de Educação Continuada, Alfabetização, Diversidade e Inclusão do Ministério da Educação (SECADI/MEC), coordenou um Grupo de Trabalho (GT) composto pelo Conselho dos Secretários Estaduais de Educação (CONSED), União dos Dirigentes Municipais de Educação (UNDIME), Confederação Nacional dos Trabalhadores na Agricultura (CONTAG), Movimento dos Trabalhadores Rurais Sem Terra (MST), Federação dos Trabalhadores da Agricultura Familiar (FETRAF), Rede de Educação do Semiárido Brasileiro (RESAB), Universidade de Brasília (UnB) e Universidade Federal de Minas Gerais (UFMG) para construir o Programa Nacional de Educação do Campo (PRONACAMPO), regulamentado em 20 de março de 2012.

O PRONACAMPO tem por objetivo central a oferta de assistência técnica e financeira aos Estados, Distrito Federal e municípios, intermediado pelo Plano de Ações Articuladas (PAR) para a implantação de uma política de educação do campo com vistas a ampliar o acesso à educação básica e ao ensino superior, mediante o emprego de ações que contribuam para aprimorar a infraestrutura das redes de ensino público, a formação inicial e continuada de professores a produção e disponibilização de materiais e recursos didático-pedagógicos às populações campesinas em todas as etapas e modalidades de ensino (BRASIL, 2013).

Salomão Mufarrej Hage (2014, p. 146) infere que a tendência da SECADI/MEC em privilegiar os Estados e municípios como interlocutores na implantação da política pública de educação do campo institucionaliza cada vez mais o processo, visto que vincula o atendimento e as ações dos programas de educação ao PAR, o que "evidencia um distanciamento entre a forma como se concretiza o PRONACAMPO e os contornos das lutas sociais responsáveis pelo percurso que gerou a sua construção".

O Fórum Nacional de Educação do Campo (FONEC, 2012), por sua vez, ao expressar as suas análises acerca das políticas públicas de educação para as populações rurais, assim como a sua implantação pelo Estado, ressalta algumas insuficiências para que possam ser caracterizadas, de fato, como políticas públicas estruturais e diferenciadas.

O FONEC destaca que os projetos e/ou programas em execução representam avanço substancial para assegurar o direito à educação às populações rurais, entretanto, ao examinar as conexões que caracterizaram o contexto histórico de construção do PRONACAMPO em sentido lato, especialmente a respeito da questão da formação técnica-profissional, constata que a expressão da hegemonia do capital no meio rural e o protagonismo das lutas empreendidas pelos movimentos sociais não são explicitados em seu conteúdo.

Portanto, o problema é estrutural, pois a sua centralidade esta voltada para a garantia de uma política pública que possibilite o avanço em direção à formação de mão de obra para o agribusiness ou para dirimir focos de tensão e conflito com os pequenos produtores agrícolas e suas organizações de classe. O Programa Nacional de Educação do Campo não é, de acordo com o FONEC, efetivamente, contrário aos interesses dos trabalhadores rurais, mas:

[...] também não representa a vitória do polo do trabalho na definição da política. Essa constatação não significa que não possamos nos reconhecer em alguns conteúdos do Programa, exatamente porque as contradições da realidade atual e as lutas dos trabalhadores do campo nesse período não deixam de ter expressão nas proposições feitas, embora não seja seu polo hegemônico. Por isso mesmo, o entendimento de que cabem estratégias de ação que confrontem o retrocesso, 
pelo menos em relação ao que se projetava com a conquista do Decreto de 2010 (FONEC, 2012, p. 17).

Para que possamos ampliar o nosso entendimento tanto dos apontamentos efetuados por Salomão Hage quanto para os alertas expressos pelo FONEC, vejamos a organização estrutural do PRONACAMPO, dividida em quantro grandes eixos e subdividida 14 ações que devem ser desenvolvidas em regime de colaboração entre a União, os Estados e os municípios.

\section{Gestão e Práticas Pedagógicas}

Ação 1 - Programa Nacional do Livro Didático Campo (PNLD Campo): produção e disseminação de materiais didáticos específicos para alunos e professores do campo na perspectiva de desenvolver os processos de ensino e aprendizagem de forma contextualizada. O Programa é disponibilizado para as escolas do campo com estudantes matriculados nos anos iniciais do ensino fundamental (PRONACAMPO, 2013, p. 4-6).

O FONEC (2013-2014) questiona como empresas e editoras comerciais que atuam em defesa da grande propriedade de terras e do capital nacional e internacional podem representar os interesses dos povos do campo no processo de produção de materiais didático-pedagógicos;

Ação 2 - Programa Nacional Biblioteca da Escola (PNBE Temático): fornecimento de obras de referência às escolas públicas, tendo em vista ampliar o entendimento de professores e alunos sobre a diversidade, inclusão e cidadania para auxiliar no desenvolvimento de valores, práticas e interações sociais.

O FONEC denuncia que muitos livros e outros materiais didático-pedagógicos produzidos por instituições de ensino superior (públicas) e por movimentos sociais do campo que consideram as experiências e as diversidades das populações campesinas têm sido ignoradas. De acordo com o Relatório Síntese do FONEC (2013, p. 8), mesmo dentre as universidades que são convidadas a construir algum material para a educação do campo, "existem aquelas que o fazem sem convocar os atores sociais do campo, como educadores com prática em sala de aula e representantes dos movimentos sociais para estabelecer parcerias na produção";

Ação 3 - Programa Mais Educação Campo: desenvolvimento de uma educação integral nas escolas do campo, mediante a disponibilização de recursos específicos para ampliar a jornada escolar diária. Em 2012, mais de 9.700 escolas do campo passaram a oferecer ensino em tempo integral com atividades de acompanhamento pedagógico e enriquecimento curricular em diversas áreas do conhecimento;

Ação 4 - Escola da Terra: a melhoria das condições de acesso, permanência e aprendizagem dos alunos do meio rural constitui o principal objetivo do Programa. A ação está concentrada no apoio à formação continuada dos professores que atuam em classes multisseriadas nos anos iniciais do ensino fundamental (PRONACAMPO, 2013, p. 6-9).

Essas quatro ações, segundo o FONEC (2013), podem ser consideradas, em certa medida, resultado da luta pela Educação do Campo; “mas, significa apenas o primeiro passo, pois há muito que se disputar nesse campo de conflito de interesses".

\section{Formação de Professores}

Ação 1 - Formação Inicial de Professores em cursos de Licenciatura em Educação do Campo (PROCAMPO) destinados à docência nos anos finais do ensino fundamental e no ensino médio, ofertados por Universidade Federais e Institutos Federais de Educação, organizados em regime de alternância. Licenciatura para Professores do Campo na modalidade presencial e a distância por meio de edital do Plano Nacional de Formação de Professores da Educação Básica (PARFOR/CAPES).

O Fórum Nacional de Educação no Campo discorda da SECADI/MEC com a oferta da Formação Inicial de Professores na modalidade a distância e reivindica a abertura de novo edital para assegurar que a formação inicial de edu- 
cadores do campo via Universidade Aberta do Brasil (UAB) ou PARFOR contemple a modalidade presencial, de forma que, no mínimo, uma licenciatura em educação do campo seja oferecida em todas as unidades da federação. Na apreensão do FONEC (2013, p. 2) é urgente possibilitar a inserção das universidades públicas em e para tal oferta, sendo mantida e enfatizada "a formação para os anos iniciais do ensino fundamental, a exemplo da Pedagogia da Terra patrocinada pelo PRONERA";

Ação 2 - Formação Continuada de Professores, Gestores e Coordenadores Pedagógicos que atuam na educação básica do campo, oferecida por instituições públicas de ensino superior no âmbito da Rede Nacional de Formação (RENAFOR) e UAB (PRONACAMPO, 2013, p. 10-11).

O FONEC (2013, p. 3) aponta a necessidade de incentivo, promoção e realização de cursos de especialização por áreas de conhecimento, tendo em vista fortalecer práticas pedagógicas inovadoras, sobretudo, aquelas destinadas às classes multisseriadas das escolas do campo; bem como, a realização de cursos de pós-graduação em nível de mestrado e de doutorado em Educação do Campo sob o regime de alternância.

\section{Educação de Jovens e Adultos/Educa- ção Profissional e Tecnológica}

Ação 1 - EJA Saberes da Terra: aumentar a escolaridade de jovens e adultos sintonizado a um projeto de desenvolvimento sustentável do campo associado à expansão da oferta da EJA nos anos iniciais e finais do ensino fundamental integrada à qualificação profissional e ensino médio.

O FONEC (2013) infere que a sociedade brasileira enfrenta um processo de desmobilização da luta em prol da EJA, apesar da constatação de que existem em nosso país aproximadamente 16 milhões de analfabetos, completamente invisíveis e à margem do sistema público de ensino. Na concepção do FONEC (2013, p. 4) a EJA foi completamente "subordinada à lógica da instrumentalização para o emprego imediato".
A disposição da EJA nas atuais políticas públicas de educação, em especial para os sujeitos que vivem e trabalham no campo no Brasil, é contrária às concepções e encaminhamentos do Fórum Nacional de Educação do Campo (2013, p. 4), na medida em que é possível verificar um retrocesso de uma política da EJA que se pretende estruturante para superar a "fragmentação, a precarização e a subordinação à lógica empresarial de instrumentalização para a empregabilidade imediata".

O FONEC (2013, p. 4) prossegue denunciando a atual política praticada pelo $\mathrm{MEC} /$ SECADI e propõe o resgate das experiências acumuladas sobre escolarização de jovens e adultos do campo "protagonizada pelos movimentos sociais, a exemplo do Programa Saberes da Terra, do PRONERA" e de inúmeras ações de alfabetização empreendidas pela e com a participação dos movimentos em defesa da educação para os sujeitos do campo;

Ação 2 - Inclusão social de jovens e adultos que vivem no campo "por meio da ampliação da Rede Federal de Educação Profissional e Tecnológica e da oferta de cursos de formação inicial e continuada para trabalhadores de acordo com os arranjos produtivos de cada região" constituem os objetivos do Programa Nacional de Acesso ao Ensino Técnico e Emprego (PRONATEC Campo) (PRONACAMPO, 2013, p. 12-13).

O FONEC (2013) afirma que o PRONATEC Campo representa uma política instituída verticalmente - de cima para baixo -, sem qualquer possibilidade de discussão acerca da definição de princípios, fundamentos, conteúdos, forma etc., nenhum contexto histórico das lutas e experiências dos movimentos sociais em defesa da educação do campo foram considerados.

O entendimento do Fórum Nacional de Educação do Campo (2013, p. 5), na correlação de forças da implantação dessa política é de distanciamento imposto pelas instâncias de poder do Estado, bem como, "pelo fato de haver muito dinheiro envolvido, que ostenta um potencial de cooptação das próprias lideranças dos trabalhadores do campo 
e dos trabalhadores da educação". O FONEC complementa essa denúncia ao afirmar que o PRONATEC Campo contribui para impedir o questionamento do acesso aos cursos técnicos com escolarização, que constituem, de fato, a primeira necessidade dos trabalhadores, independente de terem ou não consciência da importância dessa formação.

\section{Infraestrutura Física e Tecnológica}

Ação 1 - Construção de Prédios Escolares "com módulos pedagógicos de 2, 4 e 6 salas de aula, módulos administrativos, de serviço, para atividades práticas de agroecologia e quadra poliesportiva"; bem como, para a melhoria das condições de infraestrutura das escolas, com vistas a assegurar $\mathrm{o}$ atendimento das necessidades da Educação do Campo (PRONACAMPO, 2013, p. 14).

A mais incisiva delação efetuada pelo FONEC (2013) se remete ao "desinteresse" das administrações públicas municipais em edificar escolas, pois os prefeitos e os mandatários locais orientam-se pela lógica do capital, em que a "racionalidade" está concentrada na promoção do transporte escolar para crianças e jovens do meio rural.

Os prefeitos e seus staffs alegam que tanto a construção quanto a manutenção de escolas em áreas rurais são muito onerosas, considerando a folha de pagamento de professores, funcionários técnico-administrativos, despesas com água, luz, alimentação etc. Apontam uma série de entraves burocráticos exigidos pelo MEC para a construção de unidades escolares, especialmente, à escritura do terreno (devidamente legalizada), que deve pertencer ao município.

O Estado brasileiro, de acordo com o FONEC (2013, p. 7), não dispõe "de instrumentos legais suficientemente fortes para coibir a ação antieducativa do transporte escolar abusivo dos dirigentes locais", perpetuando um ciclo vicioso, que insiste no sistemático fechamento das escolas do campo para a expansão do transporte escolar.

As especificações contidas no Relatório Síntese do FONEC (2013, p. 7) reiteram que "fechar escola é crime, mesmo que essa escola do campo tenha apenas um aluno; pois escola não é escola somente para acolher alunos", muito antes e muito além, "escola é espaço social que extrapola a relação professor-aluno para entrar no âmbito da cultura e do direito dos sujeitos e da comunidade em que estão inseridos";

Ação 2 - Inclusão Digital nas escolas para os sujeitos do campo, disponibilizando computadores com acesso à internet, recursos digitais e conteúdos educacionais;

Ação 3 - Programa Dinheiro Direto na Escola Campo (PDDE Campo): disponibilizar recursos de custeio e de capital para as unidades escolares públicas municipais, estaduais e distritais do campo com alunos matriculados no ensino fundamental, tendo em vista a realização de benfeitorias em sua infraestrutura fundamental para a ocorrência de atividades educativas e pedagógicas destinadas à meIhoria da qualidade do ensino ofertado;

Ação 4 - PDDE Água e Esgoto Sanitário: disponibilizar recursos financeiros para as escolas do campo para que realizem adequações para o abastecimento de água em condições próprias para o consumo e instalação e manutenção de esgoto sanitário;

Ação 5 - Luz para Todos na Escola: atendimento prioritário no Programa Luz para Todos do Ministério de Minas e Energia. O gestor escolar fica responsável pelo encaminhamento de ofício com as coordenadas geográficas da escola à concessionária responsável pelo fornecimento de energia na localidade;

Ação 6 - Assegurar aos alunos das escolas do campo o Transporte Escolar para o campo, sobretudo até os anos finais do ensino fundamental, "com menor tempo possível no percurso residência-escola, respeitando as especificidades geográficas e culturais, bem como os limites de idade dos estudantes" (PRONACAMPO, 2013, p. 15-17).

Entendemos que uma das mais significativas deficiências de parte das políticas públicas de educação em nosso país se caracteriza pela falta de fiscalização efetiva para fazer-se cumprir. O Ministério da Educação, o Conse- 
Iho Nacional de Educação e demais autarquias de governo que regulam e regulamentam a educação brasileira, instituem pareceres, portarias, resoluções, decretos, leis, "mas na prática quem tem o poder de fechar as escolas é o município"; a reversão dessa situação somente se fará por meio de muito engajamento e movimentação "daqueles que acreditam que a educação é a única maneira efetiva de construção social" (SILVA, 2015, p. 1).

\section{CONSIDERAÇõES FINAIS}

Precisamos entender que as políticas públicas para a educação a partir da década de 1990 são decorrência direta das propostas construídas na Conferência Mundial sobre Educação para Todos, realizada em Jomtien (Tailândia) por organizações internacionais multilaterais a serviço do capitalismo, orientadas pelos fundamentos empresariais neoliberais, que priorizaram uma pressuposta descentralização da administração pública, rigorosa fiscalização e controle dos resultados, racionalização dos recursos, eficácia no emprego dos métodos, eficiência dos processos e eliminação das fronteiras entre o público e o privado.

O governo brasileiro acatou todas as orientações capitalistas neoliberais advindas do centro mundial do sistema, ou seja, dos Estados Unidos da América, por meio da ação e atuação das principais instituições financiadoras e gestoras do campo social no planeta, sobretudo, do Banco Mundial. Nesses termos são, as políticas públicas para a educação, estigmatizadas pela manutenção da centralização das decisões, definições e diretrizes para o processo pedagógico, desconcentração das ações para o nível local e pela implementação de avaliações em larga escala para controlar os resultados e promover a competição entre os cursos e as instituições, mediante o estabelecimento de uma espécie de ranqueamento. Reafirmamos aqui, que o Estado em defesa da burguesia realiza em verdade concessões, contempla parte das reivindicações da sociedade civil organizada brasileira, todavia, jamais se distancia das determinações do capital internacional.
Nesse sentido, é possível realizar algumas considerações sobre a atuação dos movimentos sociais e a implantação das políticas públicas estatais para a educação do campo, na medida em que as reivindicações, particularmente, aquelas requeridas pelo MST e pelo Movimento por Uma Educação do Campo vêm sendo parcialmente atendidas pelo Estado brasileiro como o Programa Nacional de Educação na Reforma Agrária (PRONERA), Diretrizes Operacionais para a Educação Básica do Campo, Parecer CNE/CBE n. 1/2006, que considerou dias letivos para a aplicação da Pedagogia da Alternância nos Centros Familiares de Formação por Alternância (CEFFA), Resolução CNE/CEB n. 2/2008 que definiu diretrizes complementares para o desenvolvimento de políticas públicas para a Educação do Campo, Resolução CNE/CEB n. 4/2010, que definiu as Diretrizes Curriculares Nacionais Gerais para a Educação Básica e o Decreto n. 7.352/2010, que conferiu à educação do campo a condição de política de Estado.

Diante desse cenário, é impossível negar a atuação, assim como o sucesso dos movimentos sociais na implementação de políticas para a educação do campo, bem como, não é possível negar o protagonismo cedido pela Secretaria de Educação Continuada, Alfabetização, Diversidade e Inclusão aos poderes públicos estatais e municipais na institucionalização das políticas públicas de educação para as populações do campo, visto que as ações e o atendimento vinculam-se ao Plano de Ações Articuladas, intensificando a distância entre a forma de implementação e a essência das reivindicações empreendidas pelos movimentos sociais do campo.

Tal verificação é exemplificada pelo processo histórico do Programa Nacional de Educação do Campo, sobretudo, no que se remete ao conteúdo da formação técnica-profissional ao apontar a necessidade de satisfação das demandas do sistema capitalista em prejuízo das mobilizações e lutas realizadas pelos movimentos sociais, resultando numa questão de ordem estrutural, visto que a centralidade das proposições está numa política 
que propicie o avanço da formação de mão de obra para suprir as necessidades do agribusiness e para reduzir possíveis focos de tensão e conflito com as populações rurais. Nesse sentido, o PRONACAMPO não está contra os trabalhadores, contudo, "não representa a vitória do polo do trabalho na definição da política" (FONEC, 2012, p. 17).

Dentre as contraditórias medidas adotadas pelo Estado brasileiro na formulação e implantação de políticas destinadas às populações rurais, apontamos a do transporte escolar em substituição à construção e manutenção de escolas nos locais de moradia dos rurícolas. A implementação do transporte escolar por si só representa ação antieducativa, visto que insiste no sistemático fechamento das escolas rurais, o que constitui crime. Somos partidários das interpretações e reflexões materializadas no Fórum Nacional de Educação do Campo ao expressar que o fechamento das escolas rurais tem por principal objetivo a satisfação dos interesses econômi- cos dos dirigentes políticos locais com a partiIha do transporte escolar.

Reiteramos que uma das mais relevantes responsabilidades do Estado na sociedade capitalista contemporânea é resguardar a conformação mercadológica hegemônica da educação, cada vez mais submissa e subserviente às demandas e determinações das empresas multinacionais e do capital internacional, que coordenam e conduzem a expansão do agribusiness no Brasil.

Podemos afirmar que as reformas mais amplas da educação realizadas a partir da década de 1990 pouco alteraram a histórica característica secundária da educação como direito universal e inalienável, uma vez que o fortalecimento das parcerias entre o público e o privado produziu (produz) por resultado a ampliação da dualidade estrutural, desintegrando ações, projetos e programas educacionais que se diluem em políticas focais em prejuízo das populações a que se destinam.

\section{REFERÊNCIAS}

ARROYO, Miguel Gonzalez. Que educação básica para os povos do campo? Seminário Nacional de Educação Básica nas Áreas de Reforma Agrária do MST, Luziânia/GO, set., 2005. Disponível em: <http://docslide.com.br/documents/que-educacao-basica-para-os-povos-do-campo-texto-de-miguel-arroyo.html>. Acesso em: 23 fev. 2016.

BRASIL. Chamada à ação: combatendo o fracasso escolar no Nordeste. 2 ed. Brasília/DF: Banco Mundial/UNICEF, 1997.

. Decreto n. 7.352, de 4 de novembro de 2010. Dispõe sobre a política de educação do campo e o Programa Nacional de Educação na Reforma Agrária (PRONERA). Brasília: Casa Civil, 2010. Disponível em: <http://www.planalto.gov.br/ccivil_03/_at02007-2010/2010/decreto/ d7352.htm>. Acesso em: 28 mar. 2016. NERA, 2015.

. II Pesquisa Nacional sobre a Educação na Reforma Agrária. Brasília: MDA/INCRA/PRO-

. Parecer CNE/CEB n. 1, de 1 de fevereiro de 2006. Dias Letivos para a Aplicação da Pedagogia de Alternância nos Centros Familiares de Formação por Alternância (CEFFA). Brasília: DOU, 15 de março de 2006. Disponível em: <http://portal.mec.gov.br/cne/arquivos/pdf/ pcebo01_06.pdf>. Acesso em: 27 mar. 2016.

- Programa Nacional de Educação do Campo (PRONACAMPO): Documento Orientador. Brasília: MEC/SECADI, 2013. Disponível em: <http://portal.mec.gov.br/index. php?option=com_docman\&view=download\&alias=13214-documento-orientador-do-pronacampo-pdf\&ltemid=30192>. Acesso em: 23 mar. 2016. 
. Resolução CNE/CEB n. 1, de 3 de abril de 2002. Institui Diretrizes Operacionais para a Educação Básica nas Escolas do Campo. Brasília: DOU, 9 de abril de 2002. Disponível em: <http://pronacampo.mec.gov.br/images/pdf/mn_resolucao_\%201_de_3_de_abril_de_2002. pdf>. Acesso em: 27 mar. 2016.

. Resolução CNE/CEB n. 2, de 28 de abril de 2008. Estabelece diretrizes complementares, normas e princípios para o desenvolvimento de políticas públicas de atendimento da Educação Básica do Campo. Brasília: MEC, 2008. Disponível em: <http://portal.mec.gov.br/arquivos/pdf/resolucao_2.pdf>. Acesso em: 27 mar. 2016.

. Resolução CNE/CEB n. 4, de 13 de julho de 2010. Define Diretrizes Curriculares Nacionais Gerais para a Educação Básica. Disponível em: <http://portal.mec.gov.br/dmdocuments/ rcebo04_10.pdf>. Acesso em: 27 mar. 2016.

CALDART. Roseli Salete. Sobre educação do campo. In: SANTOS, Clarice Aparecida (Org.). Por uma educação do campo: campo-políticas públicas-educação. Brasília/DF: INCRA/MDA, 2008. Disponível em: <http://www.mda.gov.br/sitemda/sites/sitemda/files/user_arquivos_64/Por\%20 uma\%20educa\%C3\%A7\%C3\%A30\%20d0\%20campo\%20n\%C3\%BAmero\%207.pdf $>$. Acesso em: 16 mai. 2014.

DUARTE, Clarice Seixas. A constitucionalidade do direito à educação dos povos do campo. In: SANTOS, Clarice Aparecida (Org.). Por uma educação do campo: campo-políticas públicas-educação. Brasília/DF: INCRA/MDA, 2008. Disponível em: <http://www.mda.gov.br/sitemda/sites/sitemda/files/user_arquivos_64/Por\%20uma\%20educa $\%$ C $3 \% A 7 \%$ C $3 \%$ A30\%20do\% 20 campo\%20 n\%C3\%BAmero\%207.pdf >. Acesso em: 16 mai. 2014.

FÓRUM NACIONAL DE EDUCAÇÃO DO CAMPO (FONEC). Oficina de Planejamento. Relatório Síntese das Conclusões e Proposições. Brasília, 13 e 14 jul., 2013. Disponível em: <http://ufrr. br/leducarr/index.php?option=com_phocadownload\&view=category\&download=51:relatorio-sintese-versao-final\&id=5:publicacoes1\&ltemid=182>. Acesso em: 23 fev. 2016.

FÓRUM NACIONAL DE EDUCAÇÃO DO CAMPO (FONEC). Seminário Nacional. Notas para análise do momento atual da Educação do Campo. Brasília, 15 a 17 ago. 2012. Disponível em: <http:/l www.gepec.ufscar.br/textos-1/legislaca01/forum-nacional-de-educacao-do-campo-2013-fonec-notas-para-analise-do-momento-atual-da-educacao-do-campo/at_download/file>. Acesso em: 3 mai. 2014.

HAGE, Salomão Mufarrej. Movimentos sociais do campo e educação: referências para análise de políticas públicas de educação superior. Revista Eletrônica de Educação, São Carlos, v. 8, n. 1, jan./abr., 2014. Disponível em: <http://www.reveduc.ufscar.br/index.php/reveduc/article/ viewFile/1018/319>. Acesso em: 12 fev. 2016.

MOLINA, Mônica Castagna. A constitucionalidade e a justicibilidade do direito à educação dos povos do campo. In: SANTOS, Clarice Aparecida (Org.). Por uma educação do campo: campo-políticas públicas-educação. Brasília/DF: INCRA/MDA, 2008. Disponível em: <http://www.mda.gov. $\mathrm{br} /$ sitemda/sites/sitemda/files/user_arquivos_64/Por\%20uma\%20educa $\%$ C $3 \% \mathrm{~A} 7 \% \mathrm{C} 3 \% \mathrm{~A} 30 \% 20$ do\%20campo\%20n\%C3\%BAmero\%207.p̄pdf>. Acesso em: 16 mai. 2014.

MOLINA, Mônica Castagna; JESUS, Sonia Meire Santos Azevedo. Reflexões a partir da tríade: campo - políticas públicas - educação. In: SANTOS, Clarice Aparecida; MOLINA, Mônica Castagna; JESUS, Sonia Meire Santos Azevedo (Orgs.). Memória e história do PRONERA: contribuições para a educação do campo no Brasil. Brasília: Ministério do Desenvolvimento Agrário, 2010. Disponível em: <http://webcache.googleusercontent.com/search?q=cache:jbljQWCkA7gJ:www. 
ufgd.edu.br/fch/ciensias-sociais-pronera/publicacoes-do-curso/livro-memoria-e-historia-do-pronera-contribuicoes-do-programa-nacional-de-educacao-na-reforma-agraria-para-a-educacao-do-campo-no-brasil-1/view+\&cd=2\&hl=pt-BR\&ct=clnk\&gl=br>. Acesso em: 23 mar. 2016.

OLIVEIRA, Ariovaldo Umbelino. A longa marcha do campesinato brasileiro: movimentos sociais, conflitos e Reforma Agrária. Estudos Avançados, São Paulo, v. 15, n. 43, set./dez., 2001. Disponível em: <http://www.scielo.br/pdf/ea/v15n43/v15n43a15.pdf $>$. Acesso em: 02 mar. 2016.

SANTOS, Flávio Reis. Políticas públicas de educação no/do campo: o transporte de estudantes no município de Morrinhos/GO. 2016. 125f. Relatório (Pós-Doutorado em Educação) - Universidade Federal de São Carlos, São Carlos/SP, 2016.

SILVA, Maria do Socorro. Da raiz à flor: produção pedagógica dos movimentos sociais e a escola do campo. In: MOLINA, Mônica Castagna. Educação do campo e pesquisa: questões para a reflexão. Brasília/DF: Ministério do Desenvolvimento Agrário, 2006. Disponível em: <http://www. gepec.ufscar.br/textos-1/teses-dissertacoes-e-tccs/educacao-do-campo-e-pesquisa-questoes-para-reflexao/view>. Acesso em: 3 mai. 2014.

\section{DADOS DOS AUTORES}

\section{FLÁVIO REIS SANTOS}

Doutor em Educação pela Universidade Federal de São Carlos. Professor do Programa de Pós-Graduação em Ambiente e Sociedade da Universidade Estadual de Goiás. Pesquisador do Grupo de Estudos e Pesquisas sobre Educação no Campo (GEPEC/UFSCar). Morrinhos/GO - Brasil. reisdossantos.flavio@gmail.com

\section{LUIZ BEZERRA Neto}

Doutor em Educação pela Universidade Estadual de Campinas. Professor da Universidade Federal de São Carlos e Coordenador do Grupo de Estudos e Pesquisas sobre Educação no Campo (GEPEC/UFSCar). São Carlos/SP - Brasil. Ibezerra@ufscar.br

Submetido em: 6-4-2017

Aceito em: 26-6-2017 